\title{
Association of IL-4RA single nucleotide polymorphisms, HLA-DR and HLA-DQ in children with Alternaria-sensitive moderate-severe asthma
}

Alan P Knutsen ${ }^{1,3^{*}}$, Hari M Vijay ${ }^{5}$, Barbara Kariuki ${ }^{1,3}$, Luis A Santiago², Ralph Graff², Jonathan D Wofford', Maulik R Shah ${ }^{1,4}$

\begin{abstract}
Background: Asthma afflicts $6 \%$ to $8 \%$ of the United States population, and severe asthma represents approximately $10 \%$ of asthmatic patients. Several epidemiologic studies in the United States and Europe have linked Alternaria sensitivity to both persistence and severity of asthma. In order to begin to understand genetic risk factors underlying Alternaria sensitivity and asthma, in these studies we examined T cell responses to Alternaria antigens, HLA Class II restriction and HLA-DQ protection in children with severe asthma.

Methods: Sixty children with Alternaria-sensitive moderate-severe asthma were compared to 49 children with Alternaria-sensitive mild asthma. We examined HLA-DR and HLA-DQ frequencies in Alternaria-sensitive asthmatic by HLA typing. To determine ratios of Th1/Th2 Alternaria-specific T-cells, cultures were stimulated in media alone, Alternaria alternata extract and Alt a1. Sensitivity to IL-4 stimulation was measured by up-regulation of CD23 on B cells.

Results: Children with Alternaria-sensitive moderate-severe asthma trended to have increased sensitivities to Cladosporium (46\% versus 35\%), to Aspergillus (43\% versus 28\%), and significantly increased sensitivities to trees (78\% versus $57 \%$ ) and to weeds (68\% versus $48 \%$ ). The IL-4RA ile75val polymorphism was significantly increased in Alternaria-sensitive moderate-severe asthmatics, $83 \%$ (0.627 allele frequency) compared to Alternaria-sensitive mild asthmatics, 57\% (0.388 allele frequency). This was associated with increased sensitivity to IL-4 stimulation measured by significantly increased IL-4 stimulated CD23 expression on CD19+ and CD86+CD19+ B cells of Alternariasensitive moderate-severe asthmatics. IL-5 and IL-13 synthesis was significantly increased in Alternaria-sensitive moderate-severe asthmatics compared to mild asthmatics to Alternaria extract and Alt a1 stimulation. The frequency of $\mathrm{HLA}-\mathrm{DQB1}{ }^{*} 03$ allele was significantly decreased in Alternaria-sensitive moderate-severe asthmatics compared to mild asthmatics, 39\% versus 63\%, with significantly decreased allele frequency, 0.220 versus 0.398 .

Summary: In children with Alternaria-sensitive moderate severe asthma, there was an increased Th2 response to Alternaria stimulation and increased sensitivity to IL-4 stimulation. This skewing towards a Th2 response was associated with an increased frequency of the IL-4RA ile75val polymorphism. In evaluating the HLA association, there was a decreased frequency of $\mathrm{HLA}-\mathrm{DQB} 1{ }^{*} 03$ in Alternaria-sensitive moderate severe asthmatic children consistent with previous studies suggest that $\mathrm{HLA}-\mathrm{DQB} 1{ }^{*} 03$ may be protective against the development of moldsensitive severe asthma.
\end{abstract}

\footnotetext{
* Correspondence: knutsenm@slu.edu

'Department of Pediatrics, Saint Louis University, St Louis, Missouri, 63104, USA
}

\section{) Biomed Central}

(c) 2010 Knutsen et al; licensee BioMed Central Ltd. This is an Open Access article distributed under the terms of the Creative Commons Attribution License (http://creativecommons.org/licenses/by/2.0), which permits unrestricted use, distribution, and reproduction in any medium, provided the original work is properly cited. 


\section{Background}

Asthma afflicts $6 \%$ to $8 \%$ of the United States population, and severe asthma represents approximately $10 \%$ of asthmatic patients [1]. This subset of severe asthmatic patients have significant morbidity and utilize health care resources disproportionately more compared to asthmatic patients with less severe disease. The current medication regimen of inhaled corticosteroids, leukotriene antagonists, and long-acting beta- 2 agonists are usually inadequate to control severe asthma. Thus, it becomes important to understand the mechanism(s) as to why these patients have pulmonary inflammation that is not adequately controlled by current treatment regimens.

Several epidemiologic studies in the United States and Europe have linked Alternaria sensitivity to both persistence and severity of asthma [2-18]. Alternaria alternata spores are the most common airborne mold in the United States and are especially prevalent in the grain-growing areas of the Midwest. In addition, significant risk for acute asthma and life-threatening asthma has been associated with Alternaria-sensitive asthma when mold spore counts have been elevated [19-23]. Recently, Pasqualotto et al [24] coined the term severe asthma associated with fungal sensitization (SAFS) in adult patients with asthma in the United Kingdom. In their studies, sensitivity to Aspergillus fumigatus was the most prevalent (66\%), followed by sensitivities to Cladosporium (52\%) and to Alternaria (34\%). Furthermore, treatment of these patients with itraconazole in a 32 week trial resulted in improved asthma quality of life (AQLQ), decreased IgE levels, and increased peak flow (PF).

The immunopathogenesis of atopic asthma is complex and multifunctional. Multiple genetic risk factors involving the inflammatory pathways, including polymorphisms of $I L-4 R A, I L-4, I L-10, I L-13$, and $C D 14$, have been described but are not present in the majority of patients. In particular, polymorphisms of $I L-4 R A$ and $I L-13$ have been associated with elevated IgE levels and asthma severity. We hypothesized that there are genotype similarities between Alternaria-sensitive moderate-severe asthma and allergic bronchopulmonary aspergillosis (ABPA). In our studies of ABPA, we identified genetic factors for the development of ABPA: (1) HLA-DR2 and HLA-DR5 restriction [25-27], and (2) $I L-4 R A$ single nucleotide polymorphism (SNP) 27,28$]$. Interestingly, the presence of HLA-DQ2 even in the presence of HLA-DR2/DR5 contributed to resistance of the development of ABPA. ABPA is a Th2 allergic hypersensitivity lung disease due to bronchial colonization of A. fumigatus that affects 1-2\% of asthmatic and 7-9\% of cystic fibrosis (CF) patients. Acute flares of ABPA are characterized by wheezing, pulmonary infiltrates, eosinophilia, increased levels of total IgE, and increased levels of anti-
A. fumigatus specific IgE, IgG and IgA antibody levels. In the present study, we examined HLA class II antigens and IL-4RA polymorphisms in Alternaria-sensitive moderate severe asthmatic children.

\section{Methods}

\section{Study Population and Sample Size}

The study population consisted of both male and female Caucasian, African-American, Hispanic children 5 to 18 years old with mild, moderate, and severe persistent asthma recruited from the Allergy and Asthma clinics at Cardinal Glennon Children's Medical Center, Saint Louis University. Children were not stratified or excluded by race of gender. Classification of asthma severity was the GINA (NHBLI) criteria using day/night symptoms, pulmonary function, and medications. Patients were evaluated for allergen sensitivities by allergy prick skin testing (Multi-Test II; Lincoln Diagnostics, Decatur, IL) to Alternaria alternata, Cladosporium herbarum, Helminthosporium sativum, Aspergillus fumigatus, Dermatophagoides pteronyssinus and farinae (housedust mites, HDM), American/German cockroach, cat hair, dog epithelium, tree pollens (oak, hickorypecan, maple/box elder, elm, ash, sycamore, walnut, juniper, birch), grass pollens (Johnson, Bermuda, June, timothy, bahia), and weed pollens (short and giant ragweed, plantain, sorrel, mugwort, hackberry, mulberry) (reagents obtained from Greer Laboratories, Lenoir, NC). Tests were regarded as positive when the mean diameter of the wheal was $\geq 3 \mathrm{~mm}$. The study group consisted of Alternaria-sensitive moderate-severe asthma compared to Alternaria-sensitive mild asthmatics. The study was fully approved by the Saint Louis University Institutional Review Board (IRB \#14611, approved 9-3-2008).

\section{IL-4RA genotyping by direct sequence analysis}

$I L-4 R A$ polymorphisms were detected as previously described $[27,28]$. Genomic variants of $I L-4 R A$ were numbered on the basis of their location in $I L-4 R A$ mRNA sequence of gene bank accession number X52425. Five previously reported IL-4RA variants ile75val (rs1805010), glu400ala (rs1805011), cys431arg (rs1805012), ser503pro (rs1805015) and gln576arg (rs1801275)(numbering including the 25 amino acid signal peptide) were genotyped. Genomic variants in $I L$ $4 R A$ were identified by direct sequencing in both the forward and reverse direction. Both forward and reverse sequencing primers were used to maintain quality control. Primer sequences and conditions are available upon request. The presence of $I L-4 R A$ nucleotide polymorphisms was examined using the NCBI Blast program (http://ncbi.nlm.nih.gov/blast/bl2seq/wblast2; accession 
number 33833); homozygous/heterozygous SNPs were detected on the nucleotide chromatograph.

\section{IL-13 genotyping by PCR restriction fragment length polymorphism analysis}

Genotyping was performed by PCR amplification of the genomic DNA region containing the arg110gln SNP (rs20541) followed by restriction digestion and comparison of size fragments to a standard size DNA ladder on gel electrophoresis, as previously described $[27,28]$. The expected product sizes are $236 \mathrm{bp}$ for the wild type sequence and $178 \mathrm{bp}$ for the arg110gln SNP. Complete digestion is confirmed by the presence of a $26 \mathrm{bp}$ fragment from the NLAIV site in the primer and in the 5' end of the PCR product. Detailed PCR conditions are available upon request.

\section{IL-4 induction of B-cell CD23 expression}

Peripheral blood mononuclear cells (PBMC) were isolated from venous blood by Ficoll-Hypaque density centrifugation as previously described [28]. PBMC were cultured at $1 \times 10^{6}$ cells $/ \mathrm{ml}$ in $1 \mathrm{ml}$ of RPMI 1640 supplemented with $10 \% \mathrm{FCS}$ for 48 hours at $37^{\circ} \mathrm{C}$ in a $6 \%$ $\mathrm{CO}_{2}$ humidified atmosphere. The cultures were stimulated with rhuIL-4 (PeproTech, Inc) at $25 \mathrm{ng} / \mathrm{ml}$. After 48 hours, the cells were washed and analyzed by flow cytometry.

\section{Flow cytometry}

PBMC prior to culture and after culture were analyzed for induction of cell surface CD23 expression on B-cells, as previously described $[27,28]$. For cultures stimulated with IL-4, PBMC were washed and stained with murine monoclonal antibody to CD23-PE and CD20 Per-CP (Becton Dickinson). PBMCs were washed and fixed with 1\% PBS buffered paraformaldehyde. Forward and sidescatter was performed to gate on the live lymphocyte population and further gated on $\mathrm{CD} 20^{+}$cells for analysis using the CellQuest program (Becton Dickinson). A minimum of 10,000 cells were counted. Quantibrite PE flow cytometry beads (Becton Dickinson) were used to quantify the number of CD23 receptors per B-cell for each experiment. The beads contain a given number of PE molecules per bead. A linear equation was calculated from which the number of CD23 receptors per cell was extrapolated, and the total number of CD23 receptors expressed per B-cell determined.

\section{TH1/Th2 cytokines and chemokines}

To determine Th1/Th2 Alternaria-specific T-cell response, Alternaria stimulated cultures were performed as previously described $[27,28] .1 \times 10^{6}$ PBL were cultured in $1 \mathrm{ml}$ volume of RPMI supplemental with $10 \%$ FCS for 1 week in a humidified $5 \% \mathrm{CO}_{2}$ atmosphere at $37^{\circ} \mathrm{C}$. Cultures were stimulated in media alone, $25 \mathrm{mcg} /$ $\mathrm{ml}$ of Alternaria alternata extract and $25 \mathrm{mcg} / \mathrm{ml}$ of Alt a1. The culture supernatant were obtained and frozen at $-70^{\circ} \mathrm{C}$ until analyzed. Alternaria extract and Alt a1 were obtained from Dr. Hari Vijay. Measurement of Th1/Th2 culture supernatant cytokines and chemokines was performed by Flex Cytometric Bead Assay (BD Pharmingen) to measure IL-4, IL-5, IL-10, IL-13, IFN- $\gamma$, synthesis, as previously described $[27,28]$.

\section{HLA typing}

In order to examine HLA-DR and HLA-DQ allelic frequencies in Alternaria-sensitive asthmatic, HLA-DR and DQ typing was performed in the HLA Laboratory as previously described [25-27]. HLA-DRB1 alleles were detected by PCR amplification of genomic DNA with sequence specific primers (PCR-SSP; Dynal, Inc, Oslo, Norway). HLA-DQ typing were performed by PCR amplification of genomic DNA by using low resolution HLA-DQB allele specific primers identifying 5 HLA-DQ alleles (One Lambda, Canoga, Park, CA).

\section{Statistical analysis}

The data for PFTs and cytokine levels were expressed as the mean \pm SD and for IgE geometric mean $x / \div$ SD . Statistical analysis using two-tailed Mann-Whitney U test was used comparing mold-sensitive moderate-severe asthma to other groups. Two-sided Fisher's exact test analysis was used comparing moderate-severe asthma to mild asthma. $P$ values less than 0.05 were considered significant, using GraphPad InStat software package.

\section{Results}

\section{Demographics}

In Table 1, the demographics of Alternaria-sensitive moderate-severe asthma is compared to Alternaria-sensitive mild asthma in children. Comparison of Alternaria-sensitive moderate-severe asthmatics to Alternaria-sensitive mild asthmatics demonstrated that the groups were age and sex matched comparably. However, there were significantly greater percentage of African-Americans in the Alternaria-sensitive moderatesevere asthma group compared to the Alternaria-sensitive mild asthma group, $70 \%$ versus $36 \%(\mathrm{p}=0.0002)$. Medication use of omalizumab ( $\mathrm{p}<0.0001)$, high-dose and medium-dose inhaled corticosteroids $(\mathrm{p}<0.0001$ and $\mathrm{p}=<0.0002$, respectively), long-acting beta agonists $(\mathrm{p}<0.0001)$ was significantly increased in Alternariasensitive moderate severe asthmatics compared to Alternaria-sensitive mild asthmatics. Immunotherapy was part of the treatment in $4 \%$ of Alternaria-sensitive moderate-severe asthmatics and 5\% of Alternaria-sensitive mild asthmatics. The percentage of patients on immunotherapy is unlikely to affect the responses to 
Table 1 Demographics of children with Alternariasensitive moderate-severe asthma compared to Alternaria-sensitive mild asthma

\begin{tabular}{|c|c|c|c|}
\hline Study & $\begin{array}{c}\text { Moderate-Severe } \\
(60)\end{array}$ & $\begin{array}{l}\text { Mild } \\
(49)\end{array}$ & $P$ \\
\hline Age, years & $11 \pm 4$ & $10 \pm 3$ & \\
\hline Sex, \% male/female & $62 / 38$ & $64 / 36$ & \\
\hline White/Black/Hispanic, \% & $30 / 70 / 0$ & $57 / 36 / 7$ & 0.0002 \\
\hline Atopic dermatitis, \% & 33 & 26 & \\
\hline \multicolumn{4}{|l|}{ Medications, \%\# } \\
\hline Omalizumab & 28 & 0 & $<0.0001$ \\
\hline ICS-H & 36 & 4 & $<0.0001$ \\
\hline ICS-M & 52 & 18 & 0.0002 \\
\hline ICS-L & 10 & 62 & $<0.0001$ \\
\hline$\angle A B A$ & 84 & 40 & $<0.0001$ \\
\hline LTRA & 77 & 64 & \\
\hline Immunotherapy, \% & 4 & 5 & \\
\hline \multicolumn{4}{|l|}{ Pulmonary function* } \\
\hline FVC & $88 \pm 15$ & $98 \pm 11$ & $<0.0001$ \\
\hline FEV-1 & $78 \pm 16$ & $94 \pm 11$ & $<0.0001$ \\
\hline FEF-25-75 & $64 \pm 23$ & $88 \pm 23$ & $<0.0001$ \\
\hline FEV-1/FVC & $85 \pm 12$ & $93 \pm 8$ & $<0.0001$ \\
\hline $\lg E, I U /\left.m\right|^{*}$ & $469 \times / \div 3.51$ & $140 \times / \div 5.01$ & 0.0001 \\
\hline \multicolumn{4}{|l|}{ Sensitivites, \%\# } \\
\hline Alternaria & 100 & 100 & \\
\hline Cladosporium & 46 & 35 & \\
\hline Helminthosporium & 32 & 28 & \\
\hline Aspergillus & 43 & 28 & \\
\hline Der $p$ and/or Der $f$ & 52 & 37 & \\
\hline Cat & 46 & 28 & \\
\hline CR & 28 & 22 & \\
\hline Trees & 78 & 57 & 0.01 \\
\hline Grasses & 56 & 54 & \\
\hline Weeds & 68 & 48 & 0.04 \\
\hline
\end{tabular}

Abbreviations: ICS-H, inhaled corticosteroid-high dose; ICS-M, -medium dose; ICS-L, -low dose; LABA, long-acting beta agonist; LTRA, leukotriene antagonist; IT, immunotherapy; FVC, forced vital capacity; FEV-1, forced expiratory volume 1 second; FEF, forced expiratory flow; CR, cockroach

Pulmonary Function data expressed presented as Mean \pm SD; IgE data

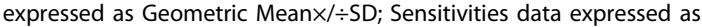
percentage of patients.

$P$ value using Mann-Whitney $\mathrm{U}$ test* and Fisher's exact test ${ }^{\#}$.

Alternaria stimulation. Results of pulmonary function studies performed on current medications revealed that FVC, FEV-1, FEF-25-75, and FEV-1/FVC ratio were significantly decreased in Alternaria-sensitive moderatesevere asthma compared to Alternaria-sensitive mild asthma. Total serum IgE levels were significantly increased in Alternaria-sensitive moderate-severe asthma compared to Alternaria-sensitive mild asthma, $469 \mathrm{IU} / \mathrm{ml}$ versus $140 \mathrm{IU} / \mathrm{ml}(\mathrm{p}<0.0001)$. Children with Alternaria-sensitive moderate-severe asthma tended to have increased sensitivities to Cladosporium and Aspergillus as well. Alternaria-sensitive moderate-severe asthma had increased sensitivities to tree pollens (78\% versus $57 \%, \mathrm{p}=0.01)$ and to weed pollens $(68 \%$ versus $48 \%, \mathrm{p}=0.04)$.

\section{IL-4RA and IL-13 polymorphisms}

The results of IL-4RA single nucleotide polymorphisms (SNP) are seen in Table 2. The presence and allele frequency of IL-4RA ile75val SNP were significantly increased in Alternaria-sensitive moderate-severe asthmatics compared to Alternaria-sensitive mild asthmatics, $83 \%$ of patients versus $57 \%$ of patients $(\mathrm{p}=0.005)$ and allele frequency 0.627 versus 0.388 $(\mathrm{p}=0.012)$. This is similar to our studies in ABPA, where the frequency of IL-4RA ile75val was significantly increased compared to Aspergillus-sensitive asthmatics and CF patients. Other IL-4RA SNPS, glu400ala, ser503pro, and gln576arg tended to be increased frequency in Alternaria-sensitive asthmatics but were not statistically significant. However, the combination of $75 \mathrm{val}$ and 576arg, 75val576arg IL-4RA, was significantly increased in Alternaria-sensitive moderate-severe asthmatics, 63\% versus $38 \%(\mathrm{p}=0.012)$. The IL-13 arg110gln SNP was similar in both moderate-severe and mild asthmatics, $31 \%$ versus $37 \%$, with similar allele frequencies, 0.178 versus 0.204 . The combination of the IL-4RA and IL-13 SNPs, 75val/576arg/110gln, was tended to be increased in Alternaria-sensitive moderate-severe asthmatics, $22 \%$ versus $8 \%(\mathrm{p}=0.07)$.

\section{Up-regulation of CD23 expression}

The up-regulation of CD23 molecules on B-cells by IL-4 stimulation is shown in Figure 1. In the absence of IL-4,

Table 2 IL-4RA and IL-13 polymorphisms in children with Alternaria-sensitive moderate-severe asthma compared to Alternaria-sensitive mild asthma

\begin{tabular}{lccc}
\hline Study & $\begin{array}{c}\text { Moderate-Severe } \\
\mathbf{( 6 0 )}\end{array}$ & $\begin{array}{c}\text { Mild } \\
\mathbf{( 4 9 )}\end{array}$ & $\boldsymbol{P}$ \\
\hline IL-4RA SNPs & $83(0.627)$ & $57(0.388)$ & $0.005(0.012)$ \\
ile75val & $61(0.390)$ & $49(0.265)$ & \\
glu400ala & $15(0.102)$ & $22(0.112)$ & \\
cys431arg & $53(0.347)$ & $37(0.214)$ & \\
ser503pro & $75(0.534)$ & $59(0.406)$ & \\
gln576arg & & & \\
IL-13 SNP & $31(0.178)$ & $37(0.204)$ & \\
arg110gln & 63 & 38 & 0.012 \\
75val/576arg & 31 & 17 & \\
75val/110gln & 22 & 8 & 0.07 \\
75val/576arg/110gln & & & \\
\hline
\end{tabular}

Abbreviations: IL-4RA, IL-4 receptor alpha chain; SNP single nucleotide polymorphisms.

Data presented as percentage (\%) of patients and in parentheses, allele frequency.

$P$ value using Fisher's exact test. 
the number of CD23 molecules decreased after 48 hours in media and was comparable in both Alternaria-sensitive moderate-severe and mild asthmatics. With IL-4 stimulation, the number of CD23 molecules per CD19+ and CD19+CD86+ B cell were significantly increased in Alternaria-sensitive moderate-severe asthmatics compared to Alternaria-sensitive mild asthmatics ( $\mathrm{p}<0.04$ and p, 0.04, respectively).

\section{Cytokine synthesis}

In Alternaria-sensitive moderate-severe asthma, Alternaria extract stimulated lymphocytes had significantly increased synthesis of IL-5 and IL-13 compared to Alternaria-sensitive mild asthma $(\mathrm{p}=0.008$ and $\mathrm{p}=0.004$, respectively) (Figure 2). Similarly, IL-5 and IL-13 synthesis was increased to Alt a1 stimulated lymphocytes in Alternaria-sensitive moderate-severe asthmatics compared to Alternaria-sensitive mild asthmatics ( $\mathrm{p}=0.07$ and $\mathrm{p}=0.007$, respectively). This would suggests that in Alternaria-sensitive moderate-severe asthma Alternaria exposure results in increased Th2 allergic inflammatory responses compared to Alternariasensitive mild asthma. Asp $\mathrm{f} 1$ and Der $\mathrm{p} 1$ stimulated IL-5 and IL-13 synthesis tended to be increased in

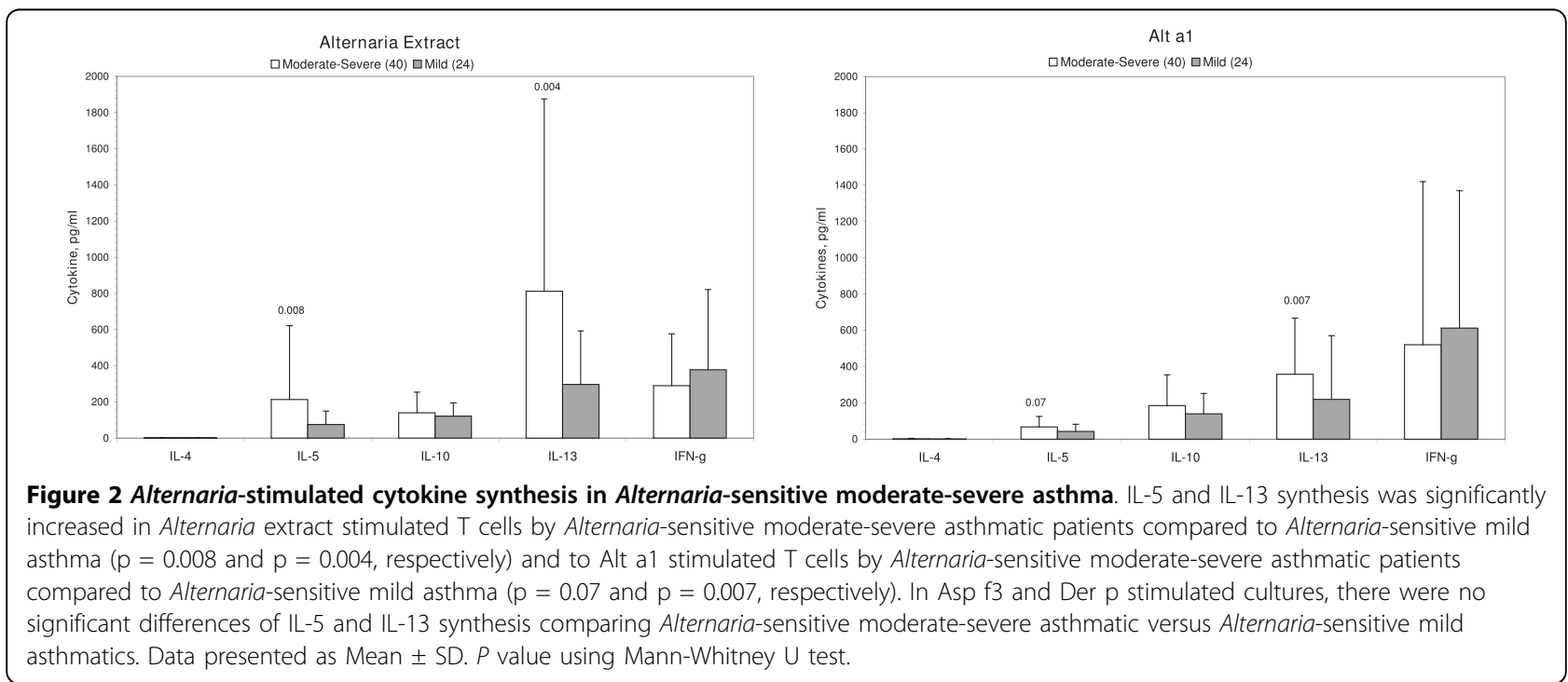


Alternaria-sensitive moderate-severe asthmatics compared to Alternaria-sensitive asthmatics but was not significant (data not shown). This suggested that the increased Th2 cytokine synthesis was specific to Alternaria stimulation.

\section{HLA-DR and HLA-DQ typing}

We subsequently examined frequencies of HLA-DR HLA-DP, and HLA-DQ in Alternaria-sensitive moderate-severe asthmatics (Table 3). The frequencies of HLADP were not significantly different comparing the groups (data not shown). The HLA-DQB1*03 allele was significantly decreased in Alternaria-sensitive moderate-severe asthmatics compared to Alternaria -sensitive mild asthmatics, $39 \%$ versus $63 \%(\mathrm{p}=0.02)$, with significantly decreased allele frequency, 0.220 versus 0.398 ( $\mathrm{p}=$ 0.007). In previous studies, Chauhan et al (32) reported that HLA-DQB1*03 was present in $51 \%$ of 98 non-atopic controls, and in the dbMHC data base http://www.ncbi. nlm.nih.gov/projects/mhc/ihwg.cgi theHLA-DQB1*03 allele frequency was significantly increased in $78.5 \%$ of 1328 individuals in North America ( $\mathrm{p}<0.0001)$. Our results suggest a significant stratification compared to the background population frequencies. These preliminary

\begin{tabular}{|c|c|c|c|}
\hline Study & $\begin{array}{c}\text { Moderate-Severe } \\
(60)\end{array}$ & $\begin{array}{l}\text { Mild } \\
(49)\end{array}$ & $P$ \\
\hline \multicolumn{4}{|c|}{ HLA-DRB1 } \\
\hline${ }^{*} 01$ & $10(0.051)$ & $8(0.041)$ & \\
\hline${ }^{*} 03$ & $29(0.153)$ & $20(0.102)$ & \\
\hline${ }^{*} 04$ & $14(0.076)$ & $29(0.153)$ & \\
\hline${ }^{*} 07$ & $24(0.127)$ & $27(0.143)$ & \\
\hline${ }^{*} 08$ & 7 (0.034) & $10(0.061)$ & \\
\hline *09 & $7(0.034)$ & $4(0.020)$ & \\
\hline${ }^{*} 10$ & $2(0.008)$ & $2(0.010)$ & \\
\hline$* 11$ & $17(0.093)$ & $33(0.184)$ & \\
\hline${ }^{*} 12$ & 7 (0.034) & $2(0.010)$ & \\
\hline$* 13$ & $37(0.195)$ & $20(0.112)$ & 0.06 \\
\hline *14 & $3(0.017)$ & $2(0.010)$ & \\
\hline *15 & $27(0.161)$ & $27(0.143)$ & \\
\hline${ }^{*} 16$ & $3(0.010)$ & $2(0.010)$ & \\
\hline \multicolumn{4}{|c|}{ HLA-DQB1 } \\
\hline${ }^{*} 02$ & $42(0.254)$ & 33 (0184) & \\
\hline${ }^{*} 03$ & $39(0.220)$ & $63(0.398)$ & $0.02(0.007)$ \\
\hline${ }^{*} 04$ & $12(0.068)$ & $8(0.041)$ & \\
\hline${ }^{*} 05$ & $31(0.161)$ & $20(0.102)$ & \\
\hline${ }^{*} 06$ & $44(0.288)$ & $51(0.276)$ & \\
\hline
\end{tabular}

Data presented as percentage of patients with allele and in parentheses allele frequency.

$P$ value using Fisher's exact test. results of decreased frequency of HLA-DQB1*03 in Alternaria-sensitive moderate-severe asthma in children is similar to that found in ABPA where HLA-DQB1*02 was decreased. It was determined that HLA-DQB1*02 was protective against the development of ABPA in Aspergillus-sensitive asthmatics and CF patients. These preliminary results of decreased frequency of HLADQB1*03 in Alternaria-sensitive moderate-severe asthmatics will need to be confirmed with a larger study population.

The allele frequency of HLA-DRB $1 * 13$ tended to be increased in Alternaria-sensitive moderate-severe asthma compared to Alternaria-sensitive mild asthma, $37 \%$ versus $20 \%(\mathrm{p}=0.06)$. The frequency of HLADRB1*13 in Alternaria-sensitive moderate-severe asthma was significantly increased compared to individuals in the dbMHC data base http://www.ncbi.nlm.nih.gov/projects/mhc/ihwg.cgi, HLA-DRB1*13 ranged from $0.5 \%$ of 1330 individuals in North America to $9.8 \%$ of 2587 individuals in Europe $(\mathrm{p}<0.0001)$.

\section{Discussion}

Alternaria alternata spores are the most common airborne mold in the United States and are especially prevalent in the grain-growing areas of the Midwest. Several epidemiologic studies in the United States and Europe have linked Alternaria sensitivity to both persistence and severity of asthma [2-18]. Many Alternaria allergens have been isolated and purified. Similar to Aspergillus allergens, these proteins have biologic activity on the respiratory epithelia in addition to inducing allergic inflammatory responses. Kauffman et al [29] reported that Alternaria and Cladosporium proteases had a direct effect on the bronchial epithelia causing pro-inflammatory cytokine synthesis and desquamation similar to A. fumigatus proteases; although Aspergillus proteases were more potent. In addition, Kheradmand et al [30] in a murine model demonstrated that Alternaria proteases promoted a chronic eosinophilic inflammation in the airways of mice exposed to these antigens. This is similar to the findings that Kurup's group identified in their murine model of allergic bronchopulmonary aspergillosis (ABPA). Another mechanism that may be operative in mold-induced asthma involves chitin, a major structural protein of the outer coating of fungi [31]. Chitin polarizes immune Th1 responses by suppressing Th2 responses. In humans, acidic mammalian chitinase degrades chitin shifting the responses toward a Th2 inflammatory response. Elevated chitinase has been associated with asthma and elevated IgE levels perhaps through an IL-13 pathway [32]. In the present studies, Alternaria-stimulated IL-5 and IL-13 synthesis was significantly increased in Alternaria -sensitive moderate-severe asthmatic children compared to Alternaria-sensitive mild asthmatics. Thus, increased 
Th2 responses to Alternaria in mold-sensitive moderatesevere asthmatic children appear to be important.

The immunopathogenesis of atopic asthma is complex and multifactorial. Allergic inflammation of the bronchial airways highlights the pathogenesis. Multiple genetic risk factors involving the inflammatory pathways, including polymorphisms of IL-4RA, IL-4, IL-10, IL-13, CD14, have been described but are not present in the majority of patients. We hypothesized that there are similarities of Alternaria-sensitive moderate-severe asthma and allergic bronchopulmonary aspergillosis (ABPA). In our studies of ABPA, we identified risk factors for the development of ABPA: (1) HLA-DR2 and HLA-DR5 restriction $[25,26]$ and (2) IL-4RA single nucleotide polymorphism (SNP) $[27,28]$.

Polymorphisms of the IL-4 receptor alpha chain $(I L-4 R A)$ and $I L-13$ have been associated with elevated IgE levels and asthma severity. There are eight naturally occurring single nucleotide polymorphisms (SNPs) of the IL4RA gene: ile75val, glu400ala, cys431arg, ser436leu, ser503pro, gln576arg, ser752ala, and ser786pro reported [33-38]. Studies have identified a number of these SNPs to be associated with atopy prevalence and asthma severity [33-38]. In the present study, IL-4RA ile75val was significantly increased in Alternaria-sensitive moderate-severe asthmatic children. Hershey et al [33] initially reported on a high prevalence of atopy and a gain-of-function in the IL-4R as measured by increased CD23 expression in patients with 576arg. This was also observed in the present study in children with Alternaria-sensitive moderate-severe asthma. Specifically, IL-4 stimulated CD23 up-regulation was observed on CD86+ B cells. CD86+ B cells are the subpopulation of $\mathrm{B}$ cells that secrete IgE, which correlates with the increased serum IgE seen in the patients with Alternaria-sensitive moderate-severe asthma. A subsequent study from Hershey's group found that the presence of these two variants (75val and 576arg) together resulted in elevated IL-4 dependent CD23 expression which was not observed when these SNPs were present alone [39]. Vladich et al (40) and Chen et al [41] reported that $I L$ 13 arg110gln was associated with elevated IgE levels and increased severity of asthma $[40,41]$. This SNP has an allele frequency of approximately $20 \%$ in the Caucasian population. The $I L-13110 \mathrm{gln}$ polymorphism is significantly more active than the wild type IL-13 in stimulating STAT-6 phosphorylation, CD23 up-regulation, and IgE synthesis. Chen et al [41] also reported that combination of the $I L-4 R A$ SNPs, 75val and 576arg, and $I L-13$ SNP, 110gln, have been associated with atopy and asthma. This was observed in $22 \%$ of the children with Alternaria-sensitive moderate-severe asthma compared to $8 \%$ of children with mild asthma. In addition,
Wenzel et al (1) reported that there was increased frequency of the ser503pro IL-4RA polymorphism in adults with severe asthma, which was not seen in this study.

In ABPA, we previously reported HLA-DR2 (HLADRB1*15 and B1*16)/DR5 (HLA-DRB1*11 and HLA$\mathrm{DRB}^{*}$ 12) restriction, and in particular HLA-DRB1*1501 and HLA-DRB1*1503 genotypes as a risk factor for the development of ABPA $[25,26]$. Interestingly, the presence of HLA-DQ2 even in the presence of HLA-DR2/ DR5 contributed to resistance of the development of ABPA. In previous studies, we have identified HLA-DR restriction to Alternaria allergens in the development of Alternaria-sensitive moderate-severe asthma data not shown). In addition, HLA-DRB1*03 was significantly increased in mold sensitive moderate-severe asthmatic children compared to mold sensitive mild asthmatics. In Alternaria-sensitive moderate-severe asthmatic children the frequency of HLA-DRB1*03 trended to be increased but was not significant. However, HLA-DQB1*03 was significantly decreased in Alternaria-sensitive moderatesevere asthmatics. In previous studies, HLA-DQB1*03 was demonstrated to be associated with decreased Alternaria stimulated IL-5 and IL-13 synthesis. Thus, HLA-DQ3+ appears to be protective of development of Alternaria-sensitive severe asthma.

\section{Conclusions}

In summary, we hypothesize that in children with Alternaria-sensitive moderate-severe asthma that there are genetic risk factors similar to those identified in ABPA. These include HLA-DR restriction, HLA-DQB1*03 protection, and IL-4RA polymorphisms. We propose that there is increased sensitivity to IL-4 and IL-13 mediated activities secondary to polymorphisms of $I L-4 R A$. This is associated with HLA-DRB1*03 restriction and decreased HLA-DQB1*03 protection to Alternaria antigens that results in Alternaria stimulated skewing of Alternaria -specific Th2 cells, increased B-cell activity, and increased bronchial epithelial allergic inflammatory responses.

\section{Key words and Abbreviations}

Asthma

Alternaria alternata

HLA class II antigens

Th2 cytokines

SNP: single nucleotide polymorphism; IL-4RA: interleukin 4 receptor alpha chain.

\section{Acknowledgements}

The authors appreciate the willing participation of the patients who participated in this study. The study was partially funded by a grant from 
Genentech/Novartis CIGE025A US 32T. The author (APK) appreciates the helpful comments and critique of Dr. Raymond G. Slavin.

\section{Author details}

${ }^{1}$ Department of Pediatrics, Saint Louis University, St Louis, Missouri, 63104 USA. ${ }^{2}$ Department of Surgery, (HLA Laboratory) Saint Louis University, St Louis, Missouri, 63104, USA. ${ }^{3}$ Divisions of Allergy \& Immunology, Saint Louis University, St Louis, Missouri, 63104, USA. ${ }^{4}$ Department of Genetics, Saint Louis University, St Louis, Missouri, 63104, USA. ${ }^{5}$ Health Canada, Healthy Environments and Consumer Safety Branch, Hazard Identification Division, Ottawa, ON, K1A 0K9, Canada.

\section{Authors' contributions}

APK conceived of the study and participated in its design and coordination. HMV provided Alternaria extract and recombinant Alt a1. BK performed cell cultures and PCR studies. LAS performed HLA studies. RG provided expertise in HLA studies. JDW provided statistical support. MRS provided technical expertise in PCR studies. All authors read and approved the final manuscript.

\section{Competing interests}

The authors declare that they have no competing interests.

Received: 2 January 2010 Accepted: 18 March 2010

Published: 18 March 2010

\section{References}

1. Wenzel SE, Busse WW, National Heart, Lung, and Blood Institute's Severe Asthma Research Program: Severe asthma: lessons from the severe asthma research program. J Allergy Clin Immunology 2007, 119:12-21.

2. Denning DW, O'Driscoll BR, Hogaboam CM, Bowyer P, Niven RM: The link between fungi and severe asthma: a summary of the evidence. Eur Respir J 2006, 27:615-626.

3. Bush RK, Prochnau JJ: Alternaria-induced asthma. J Allergy Clin Immunol 2004, 113:227-234

4. Cantani A, Ciaschi V: Epidemiologogy of alternaria alternate allergy: a prospective study in 6840 Italian asthmatic children. Eur Rev Med Pharmacol Sci 2004, 8:289-294.

5. Neukirch C, Henry C, Leynaert B, Liard R, Bousquet J, Neukirch F: Is sensitization to Alternaria alternata a risk factor for severe asthma? A population-based study. J Clin Allergy Immunol 1999, 103:709-711.

6. Zuereik M, Neukirch C, Leynaert B, Liard R, Bousquet J, Neukirch F, European Community Respiratory Health Survey: Sensitization to airborne moulds and severity of asthma: cross-sectional study fro European Community respiratory health survey. BMJ 2002, 325:411-414.

7. O'Driscoll BR, Hopkinson LC, Denning DW: Mold sensitization is common amongst patients with severe asthma requiring multiple hospital admissions. BMC Pulm Med 2005, 5:4.

8. Nolles G, Hoekstra MO, Schouten JP, Gerritsen J, Kauffman HF: Prevalence of immunoglobulin E for fungi in atopic children. Clin Exp Allergy 2001, 31:1564-1570

9. Stark PC, Burge HA, Ryan LM, Milton DK, Gold DR: Fungal levels in the home and lower respiratory tract illnesses in the first year of life. Am J Respir Crit Med 2003, 168:232-237.

10. Halonen M, Stern DA, Lohman C, Wright AL, Brown MA, Martinez FD: Two subphenotypes of childhood asthma that differ in maternal and paternal influences of asthma risk. Am J Respir Crit Care Med 1999, 160:564-570.

11. Downs SH, Mitakakis TZ, Marks GB, Car NG, Belousova EG, Leuppi JD: Clinical importance of Alternaria exposure in children. Am J Respir Crit Care Med 2001, 164:455-459.

12. Delfino RJ, Zeiger RS, Seltzer JM, Street DH, Matteucci RM, Anderson PR, Koutrakis $P$ : The effect of outdoor fungal spore concentrations on daily asthma severity. Environ Health Perspect 1997, 05:622-635.

13. Nelson HS, Szefler SJ, Jacobs J, Huss K, Shapiro G, Sternberg AL: The relationships among environmental allergen sensitization, allergen exposure, pulmonary function, and bronchial hyperresponsiveness in the Childhood Asthma Management Program. J Allergy Clin Immunol 1999, 104:775-785.

14. Perzanowski MS, Sporik R, Squillace SP, Gelber LE, Call R, Carter M, PlattsMills TA: Association of sensitization to Alternaria allergens with asthma among school-age children. J Allergy Clin Immunol 1998, 101:626-632.
15. Peat JK, Tovey E, Mellis CM, Leeder SR, Woolcock AJ: Importance of house dust mite and Alternaria allergens in childhood asthma: an epidemiological study in two climatic regions of Australia. Clin Exp Allergy 1993, 23:812-820.

16. Halonen M, Stern DA, Wright AL, Taussig LM, Martinez FD: Alternaria as a major allergen for asthma in children raised in a desert environment. Am J Respir Crit Care Med 1997, 155:1356-1361.

17. Dales RE, Cakmak S, Burnett RT, Judek S, Coates F, Brook JR: Influence of ambient fungal spores on emergency visits for asthma to a regional children's hospital. Am J Respir Crit Care Med 2000, 162:2087-2090.

18. Martinez FD: Progression of asthma from childhood to adolescence. Eur Respir Rev 1997, 40:8-10.

19. Targonski PV, Persky WW, Ramekrishan V: Effect of environmental molds on risk of death from asthma during the pollen season. J Allergy Clin Immunol 1995, 95:955-961.

20. Black PN, Udy AA, Broide SM: Sensitivity to fungal allergens is a risk factor for life-threatening asthma. Allergy 2000, 55:501-504.

21. Celenza A, Fothergill J, Kupek E, Shaw RJ: Thunderstorm associated asthma: a detailed analysis of environmental factors. BMJ 1996, 312:604-607.

22. Rosas I, McCartney HA, Payne RW, Calderón C, Lacey J, Chapela R, RuizVelazco S: Analysis of the relationships between environmental factors (aeroallergens, air pollution, and weather) and asthma emergency admissions to a hospital in Mexico City. Allergy 1998, 53:394-401.

23. Dales RE, Cakmak S, Judek S, Dann T, Coates F, Brook JR, Burnett RT: The role of fungal spores in thunderstorm asthma. Chest 2003, 123:745-750.

24. Pasqualotto A, Powell G, Niven R, Denning DW: Evaluation of the effect of antifungal therapy on severe asthma with fungal sensitization (SAFS) and allergic bronchopulmonary aspergillosis. Respirology 2009, 14:1121-1127.

25. Bellone CJ, Chauhan B, Knutsen AP, Hutcheson PS, Slavin RG: MHC class II restriction of cloned T-cells reactive with the Aspergillus fumigatus allergen, Asp f1. J Allergy Clin Immunol 1995, 95:356.

26. Chauhan B, Santiago L, Hutcheson PS, Schwartz HJ, Spitznagel E, Castro M Slavin RG, Bellone $\mathrm{CJ}$ : Evidence for the involvement of two different MHC class II regions in susceptibility or protection in allergic bronchopulmonary aspergillosis. J Allergy Clin Immunol 2000, 106:723-729.

27. Knutsen AP, Kariuki B, Santigo L, Hutcheson PS, Brusatti J, Slavin RG, Bellone CJ, Shah MR: HLA-DR, IL-4RA, and IL- 10: Genetic risk factors in allergic bronchopulmonary aspergillosis. Pediatr Asthma Allergy Immunol 2009, 21:185-190.

28. Knutsen AP, Kariuki B, Consolino JD, Warrier MR: IL-4 alpha chain receptor (IL-4RA) polymorphisms in allergic bronchopulmonary aspergillosis. Clin Mol Allergy 2006, 3:1-6.

29. Kauffman HF, Tomee JF, Riet van de MA, Timmerman AJ, Borger P. Protease-dependent activation of epithelial cells by fungal allergens leads to morphologic changes and cytokine production. J Allergy Clinic Immunol 1193, 105:1185-2000.

30. Kheradmand F, Kiss A, Xu J, Lee SH, Kolattukudy PE, Corry DB: A proteaseactivated pathway underlying Th cell type 2 activations and allergic lung disease. J Immunol 5911, 169:5904-2002.

31. Chatterjee R, Batra J, Das S, Sharma SK, Ghosh B: Genetic association of acidiic mammalian chitanse with atopic asthma and serum total lgE levels. J Allergy Clin Immunol 2008, 122:202-208.

32. Ober C, Tan Z, Sun Y, Possick JD, Pan L, Nicolae R, Radford S, Parry RR, Heinzmann A, Deichmann KA, Lester LA, Gern JE, Lemanske RF Jr, Nicolae DL, Elias JA, Chupp GL: Effect of variation in CHI3L1 on serum YKL-40 level, risk of asthma, and lung function. N Engl J Med 2008, 358:1682-1691.

33. Hershey GKK, Friedrich MF, Esswein LA, Thomas ML, Chatila TA: Association of atopy with a gain-of-function mutation in the interleukin-4 receptor a chain. N Engl J Med 1997, 37:1720-1725.

34. Kruse S, Japha T, Tedner M, Sparholt SH, Forster J, Kuehr J, Deichmann KA The polymorphisms S503P and Q576R in the interleukin-4 receptor alpha gene are associated with atopy and influence the signal transduction. Immunology 1999, 96:365-377.

35. Ober C, Leavitt SA, Tsalenko A, Howard TD, Hoki DM, Daniel R, Newman DL, Wu X, Parry R, Lester LA, Solway J, Blumenthal M, King RA, Xu J, Meyers DA, Bleecker ER, Cox NJ: Variation in the interleukin-4 receptor alpha gene confers susceptibility to asthma and atopy in ethnically diverse populations. Am J Hum Genet 2000, 66:517-526. 
36. Deichmann KA, Heinzmann A, Forster J, Dischinger S, Mehl C,

Brueggenolte $E$, Hildebrandt F, Moseler M, Kuehr J: Linkage and allelic association of atopy and markers flanking the IL-4-receptor gene. Clin Exp Allergy 1998, 28:151-155.

37. Mitsuyasu H, Izuhara K, Mao XQ, Gao PS, Arinobu Y, Enomoto T, Kawai M, Sasaki S, Dake Y, Hamasaki N, Shirakawa T, Hopkin JM: lle50Val variant of IL4R alpha upregulates IgE synthesis and associates with atopic asthma. Nat Genet 1998, 19:119-120.

38. Rosa-Rosa L, Zimmermann N, Bernstein JA, Rothenberg ME, Khurana Hershey GK: The R576 IL-4 receptor alpha allele correlates with asthma severity. J Allergy Clin Immunol 1999, 104:1008-1014.

39. Risma KA, Wang N, Andrews RP, Cunningham CM, Ericksen MB, Bernstein JA, Chakraborty R, Hershey GK: V75R576 IL-4 receptor alpha is associated with allergic asthma and enhanced IL-4 receptor function. J Immunol 2002, 169:1604-1610.

40. Vladich FD, Brazille SM, Stern D, Peck ML, Ghittoni R, Vercelli D: IL-13 $\mathrm{R} 130 \mathrm{Q}$, a common variant associated with allergy and asthma, enhances effector mechanisms essential for human allergic inflammation. J Clin Invest 2005, 115:747-754.

41. Chen W, Ericksen MB, Hershey GKK: Functional effect of the R110Q IL13 genetic variant alone and in combination with IL4RA genetic variants. J Allergy Clin Immunol 2004, 114:553-560.

doi:10.1186/1476-7961-8-5

Cite this article as: Knutsen et al: Association of IL-4RA single nucleotide polymorphisms, HLA-DR and HLA-DQ in children with Alternaria-sensitive moderate-severe asthma. Clinical and Molecular Allergy 2010 8:5.

\section{Submit your next manuscript to BioMed Central and take full advantage of:}

- Convenient online submission

- Thorough peer review

- No space constraints or color figure charges

- Immediate publication on acceptance

- Inclusion in PubMed, CAS, Scopus and Google Scholar

- Research which is freely available for redistribution

Submit your manuscript at www.biomedcentral.com/submit

C Biomed Central 